\title{
ESTUDIO EPIGRÁFICO Y ARQUEOMÉTRICO DE LA PLACA FUNERARIA DE CELA (MOS, PONTEVEDRA): NUEVAS PROPUESTAS DE INTERPRET A CIÓN
}

\author{
S. GONZÁLEZ SOUTELO ${ }^{(1)}$, A. GUTIÉRREZ GARCIA-M. ${ }^{(2)}$, H. GONZÁLEZ BORDAS ${ }^{(3)}$ \& M.-C. SAVIN ${ }^{(4)}$
}

Resumen:

\begin{abstract}
La epigrafía en Galicia es abundante y conocida, pero la aplicación de estudios interdisciplinares y nuevas metodologías analíticas puede proporcionar una rica información que matice e incremente la información presente en estas piezas. El caso de la placa funeraria de mármol localizada en Cela (Mos, Pontevedra) es un excepcional ejemplo de las múltiples posibilidades que tiene el estudio arqueométrico del soporte. Así, la identificación del material empleado como mármol procedente del Anticlinal de Estremoz (Portugal) y la reinterpretación epigráfica realizada, introducen nuevos elementos para la lectura histórica-arqueológica de esta pieza y consecuentemente de su significado en el contexto de la arqueología romana en el NW Peninsular.

Palabras claves: Mármol del Anticlinal de Estremoz, epigrafía funeraria romana, importación, reuso, Gallaecia .
\end{abstract}

Abstract:

\begin{abstract}
Epigraphic and archaeometric study of the Roman funerary plaque of Cela (Mos, Pontevedra): new approach to its interpretation

Galician epigraphy is a large corpus of well-known materials. Nevertheless, the application of interdisciplinary studies and new analytical methods can provide new and rich data to increase the range of information we obtain from them. The case of the funerary plaque found at Cela (Mos, Pontevedra) is an exceptional example of the potential that an archaeometrical study of the epigraphic medium can offer. In this case, the identification of the marble employed as coming from the Estremoz Anticline (Portugal) and the epigraphical review, provide new aspects for the historical interpretation of this piece, and, consequently a new contribution to the Roman archaeology of the NW Iberian Peninsula.
\end{abstract}

Key-words: Marble from the Estremoz Anticline, Roman funerary epigraphy, imports, reuse, Gallaecia.

\section{INTRODUCCIÓN}

La pieza objeto de este estudio fue descubierta en la iglesia parroquial de S. Pedro de Cela, ayuntamiento de Mos (Pontevedra, Fig. 1a) a mediados del s. XIX, aunque solo unos años después se trasladaría al Museo Arqueológico provincial de Pontevedra donde actualmente se exhibe en una de sus salas.

Si bien, inicialmente podría tratarse de uno más de los muchos epígrafes de época romana localizados en Galicia, consideramos necesario llamar la atención sobre esta pieza a raíz de dos aspectos: fundamentalmente la calidad del soporte (mármol, de gran calidad y posible procedencia foránea; frente al granito, material local predominante en este tipo de piezas ${ }^{1}$ ); pero también por la calidad y cuidada factura de su inscripción, que implica la intervención de un lapicida especializado y que, a día de hoy, la sitúa entre las de mejor calidad de las encontradas en el extremo NW de la península Ibérica.

Conscientes de esa realidad, hemos planteado un estudio integrado de este epígrafe, contemplando no sólo la revisión de los aspectos que ya han sido abordados anteriormente por otros investigadores (contextualización en relación al lugar de hallazgo, lectura epigráfica y aspectos formales), sino también el estudio arqueométrico del material empleado en su elaboración, aspecto que a menudo se obvia en el estudio de este tipo de piezas y que puede representar una aportación trascendental para la comprensión del fenómeno epigráfico en toda su complejidad ${ }^{2}$. El interés de este tipo de estudios, esenciales para identificar la procedencia

${ }^{(1)}$ Dep. de Prehistoria y arqueología, Universidad Autónoma de Madrid UAM/MIAS y GEAAT, Universidade de Vigo. silvia.gonzalezs@uam.es

${ }^{(2)}$ Unitat d'Estudis Arqueomètrics. Institut Català d'Arqueologia Clàssica. agutierrez@icac.cat,

${ }^{(3)}$ Centro CIL II. Universidad de Alcalá. hgonzalezbordas@gmail.com

${ }^{(4)}$ Institut de recherche sur les Archéomatériaux - Centre de Recherche en Physique Appliquée à l'Archéologie, UMR 5060 CNRS - Université de Bordeaux Montaigne y Dep. de Petrología y Geoquímica, Universidad de Zaragoza. marie.claire.savin@gmail.com

${ }^{1}$ En ese sentido, hasta el momento, solo hemos identificado en territorio gallego 16 inscripciones realizadas en mármol (de época romana y tardorromana), del

total de epígrafes publicados hasta el momento. La idea de que la materia prima constituye uno de los elementos más importantes a tener en cuenta en el estudio del soporte epigráfico está a día de hoy bie afianzada (Susini 1966; 1982; Mayer 1999; Ruiz Gutierrez 2013). En el caso hispano, esta aproximación al fenómeno epigráfico ha experimentado un impulso importante en fechas recientes, con trabajos en los que se considera detenidamente el tipo de material empleado (Gorostidi 2010; Jordán y Andreu 2013; Ramíre Sánchez 2014). Sin embargo, éstos son aun escasos y se circunscriben principalmente al noreste peninsular, con mayor tradición en el estudio interdisciplinar entre epigrafía y arqueometría (Alvarez \& Mayer 1987; Rodà 2005; Gutiérrez García-M. y Rodà 2012; Mayer 2012; Gorostidi \& López Vilar 2015; Gorostidi et al. 2018). 


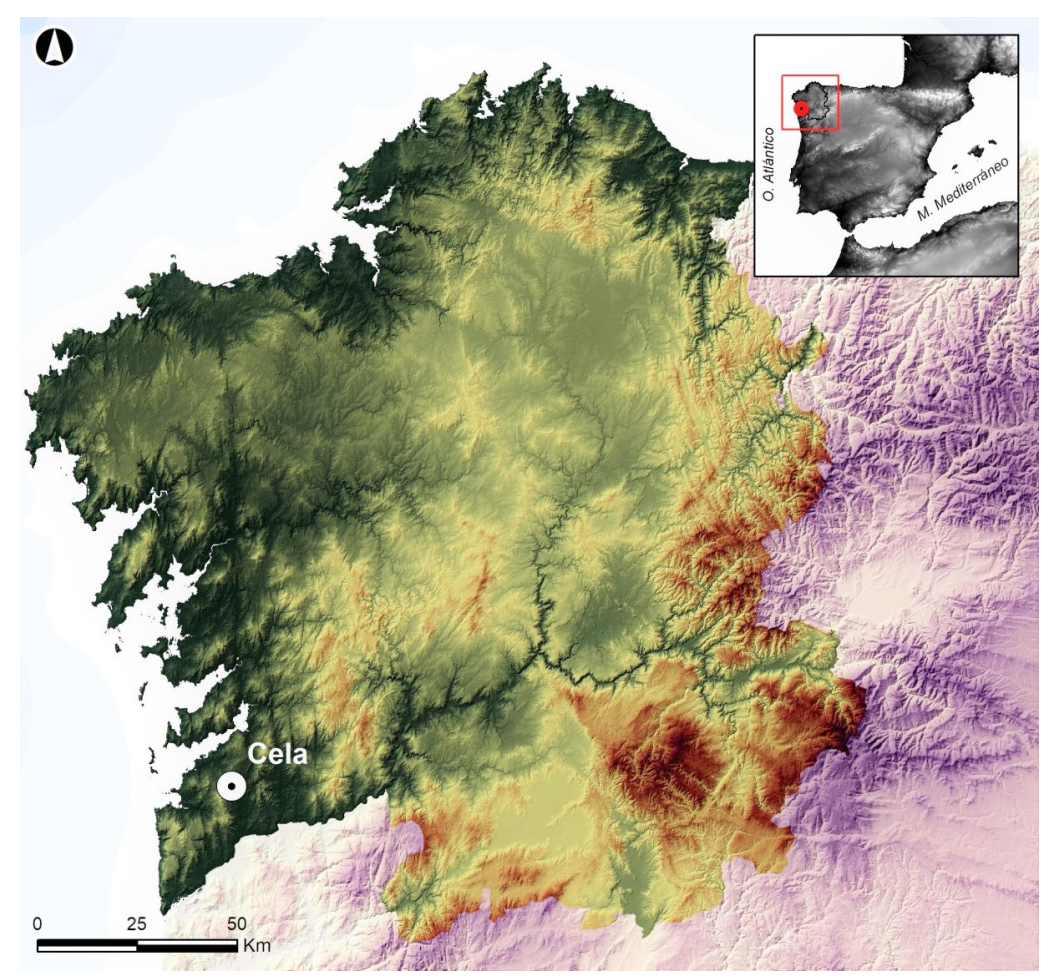

Fig. 1a. Localización de la parroquia de Cela (Mos, Pontevedra)

Fig. 1a. Location of the parish of Cela (Mos, Pontevedra).

de la materia prima, va más allá de lo que concierne específicamente a la comprensión de un determinado objeto. En efecto, desde una perspectiva mucho más global, la identificación de los mármoles permite asimismo entender aspectos socioeconómicos del mundo romano vinculados a la "extracción del material, trabajos a pie de cantera, comercialización del producto y elaboración final en el lugar de destino o de utilización" (Lapuente \& Álvarez 2012:73).

De esta manera, además de los nuevos datos derivados de cada una de estas facetas, la combinación de estudios interdisciplinares será esencial para entender determinados aspectos relacionados con la producción y uso de esta inscripción. Asimismo, gracias a que su estudio se desarrolla en el contexto de varios proyectos de investigación sobre el empleo del mármol en Galicia en época romana $^{3}$, entendemos que esta pieza, escasamente publicada, aporta nuevos datos para comprender algunos aspectos vinculados a la sociedad y a los flujos comerciales de estos objetos con una clara dimensión vinculada al lujo y al prestigio dentro del NW peninsular.

\section{CONTEXTO DEL HALLAZGO}

El epígrafe que nos ocupa fue dado a conocer ya en el s. XIX por el padre Fita (Fita \& Fernández -Guerra y Orbe 1880: 92) indicando que había sido descubierto solo unos años antes de su publicación al "desenvolver" el suelo en el atrio de la iglesia parroquial de S. Pedro de Zela (sic) ${ }^{4}$. Este autor indica que la vio Pascual Carrascosa, secretario de Juan María Valero, obispo de Tui, quien la describió como una pieza de "blanco mármol de Carrara" por lo que fue reubicada en la pared de la Casa de Obra, contigua al templo, momento en el que probablemente se practicaron los agujeros que hoy día presenta para facilitar su colocación.

En 1896 esta pieza fue cedida a la Sociedad Arqueológica de Pontevedra por mediación del Obispo de Tui, y desde ese momento pasó a formar parte de los fondos del Museo Arqueológico Provincial de Pontevedra (Filgueira Valverde \& D'Ors 1955, IRG III 39: p. 65). Como se menciona en esta obra, Ceán Bermúdez hace referencia también a este lugar (citado como S. Pedro de Bela [sic]), aunque sin hacer mención a la lápida, indicando ${ }^{3}$ Nos estamos refiriendo, por una parte, al proyecto de investigación Marmora Galicia, iniciado en 2012 en el marco del proyecto HAR2011-25011 y continuado
dentro de los proyectos HAR2015-65319-P (MINECO/FEDER) y PGC2018-099851-A-I00 (MCIU/AEI/FEDER, UE); y por otra parte al proyecto ROMAE
puesto en marcha en 2016 dentro del Lab Ex Sciences Archéologiques de Bordeaux (programa financiado por la ANR, n'ANR-10-LABX-52).
${ }^{4}$ Iglesia parroquial construida en el s. XVIII, sin indicios de la construcción previa a esta fundación (Pereira Molares 2006: 204-205). Sin embargo, el padre
Flórez (Flórez 1790: 40) menciona que hubo una primitiva iglesia, construida por S. Fructuoso, que formaría parte de un monasterio, pero existen dudas sobre la
localización de esa construcción. 
que aparecieron restos de "cimientos y paredones de argamasa, ladrillos redondos" que pone en relación con los restos de alguna ciudad antigua perteneciente al populus de los grovios (Ceán Bermúdez 1832: 222), dentro del conuentus Bracarensis.

Sin embargo, pese a esas indicaciones, no tenemos constancia de hallazgos significativos de época romana en las inmediaciones de la iglesia ${ }^{5}$ a los que se pudiera vincular este hallazgo. Aunque en el término municipal de Mos no se han estudiado por el momento asentamientos de tipología romana $^{6}$, sí se han realizado hallazgos puntuales de materiales de esta cronología, como una basa romana de gran tamaño y calidad encontrada en la próxima aldea de Atín, a algo más de $1 \mathrm{~km}$ de distancia de la iglesia parroquial en donde se localizó este epígrafe; o un fragmento de estela funeraria de granito localizada en la iglesia parroquial de Louredo (CIRG II 136) que ha sido vinculado a una necrópolis de época romana ${ }^{7}$. Otro aspecto de interés para el caso que nos ocupa, es el paso de la vía XIX del Itinerario Antonino a menos de $5 \mathrm{~km}$ de distancia de esta iglesia de acuerdo con el desarrollo propuesto para esta vía por Rodríguez Colmenero et al. (2004), en el tramo comprendido entre las mansiones de Tude y Burbida. La identificación de este trazado vendría reforzada por la aparición in situ en este ayuntamiento de un miliario en el lugar de Santiaguiño de Antas (Fig. 1b), en la parroquia de Guizán. Igualmente, el recorrido que realizaría esta vía, al menos por esta parte meridional de Galicia, fue recuperado por el Camino Portugués a Santiago de Compostela, como principal vía de comunicación por este ámbito.

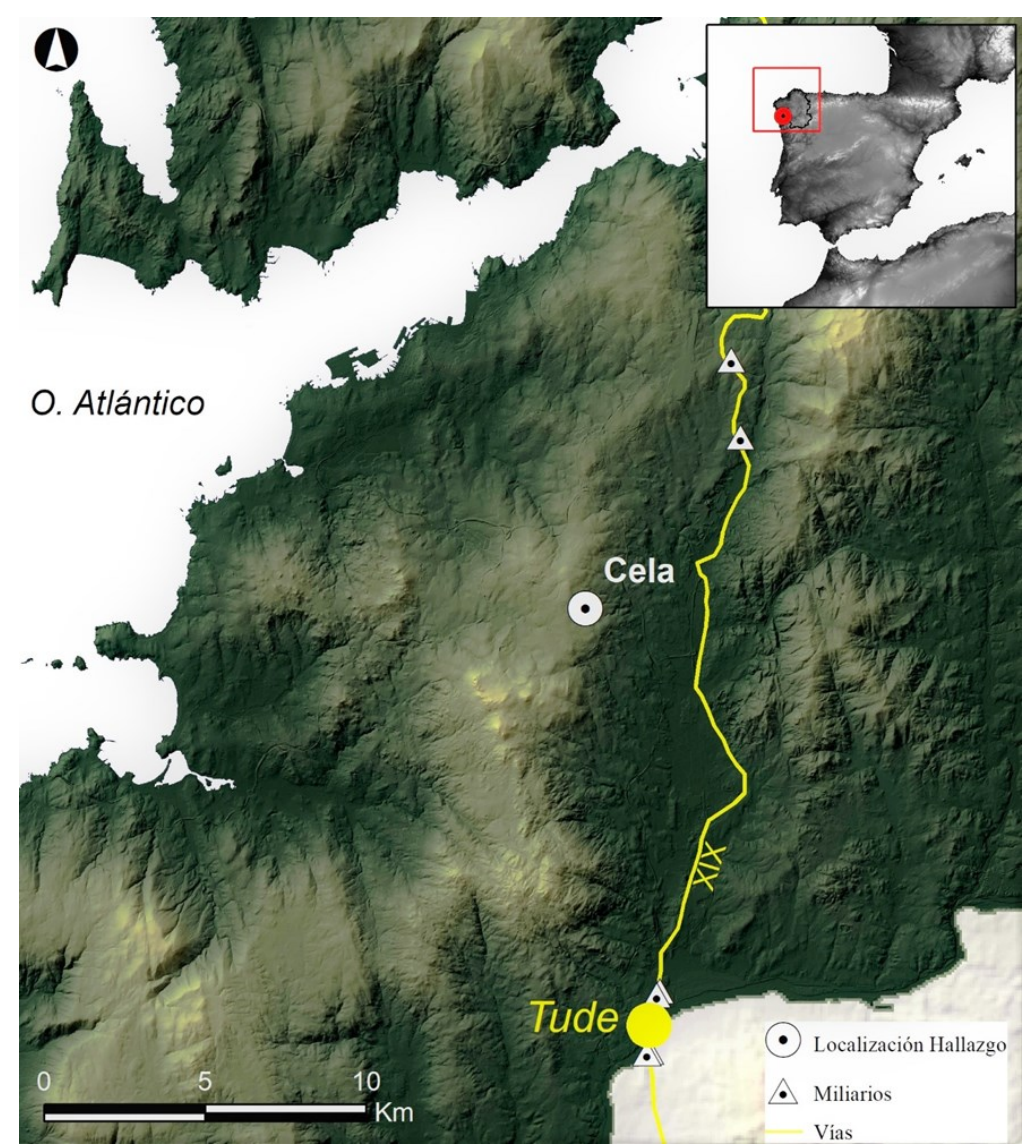

Fig. 1b. Localización de la iglesia parroquial de Cela, respecto al enclave Tude (Tui), al trazado de la vía XIX a su paso por el ayuntamiento de Mos y los miliarios más próximos, según A. Rodríguez Colmenero et al. (2004).

Fig. 1b. Location of the parish church of Cela, in relation with Tude (Tui), the Antonine Itinerary's XIX road in its way through the current territory of Mos and the Roman milestones found in its proximities (according A. Rodríguez Colmenero et al. 2004).

\footnotetext{
${ }^{5}$ En el CIRG II 7* (Baños Rodríguez 1994, CIRG II 7: pg345), de acuerdo con los documentos de C. Sampedro conservados en el Museo de Pontevedra, se preserva una nota con referencia a un epígrafe muy similar al que nos ocupa, con las mismas características formales y misma procedencia, diferenciándose solo en el texto (O ARGECLLIANI / CANANI MAGNI / FILII). Si bien se plantea que pueda ser una copia de la pieza en cuestión, parece tratarse de la descripción de la misma pieza con una reproducción del texto errónea.

${ }^{6}$ El enclave poblacional de época romana más próximo sería el de la mansio y aglomerado secundario de Tude (Pérez Losada 2002; González Soutelo 2007), ubicado a $15 \mathrm{~km}$ al sur en línea recta. Esa población sería un importante nodo de comunicaciones tanto de los ejes viarios terrestres (N-S, así como costa-interior), como de la vía fluvial por el río Miño.

${ }^{7}$ PXOM Concello de Mos, publicado en el DOG de 2017/02/08, ficha X_054.
} 


\section{ESTUDIO DE LA PIEZA}

Se trata de una placa funeraria expuesta en una de las salas del Museo Arqueológico Provincial de Pontevedra, con el número de inventario 2020(Fig. 2) . $^{8}$.

Formalmente aparece parcialmente recortada por su lado izquierdo e inferior, posiblemente para su reutilización en posición secundaria, por lo que parte del texto inscrito aparece seccionado. Asimismo, presenta dos perforaciones en su lado izquierdo posiblemente realizadas tras su descubrimiento para ser recolocada en el atrio de la Iglesia, antes de ser trasladada al Museo Arqueológico. También se documenta la presencia de restos de cal en su parte posterior como consecuencia de esa posible reutilización (CIRG, II, 135:319).

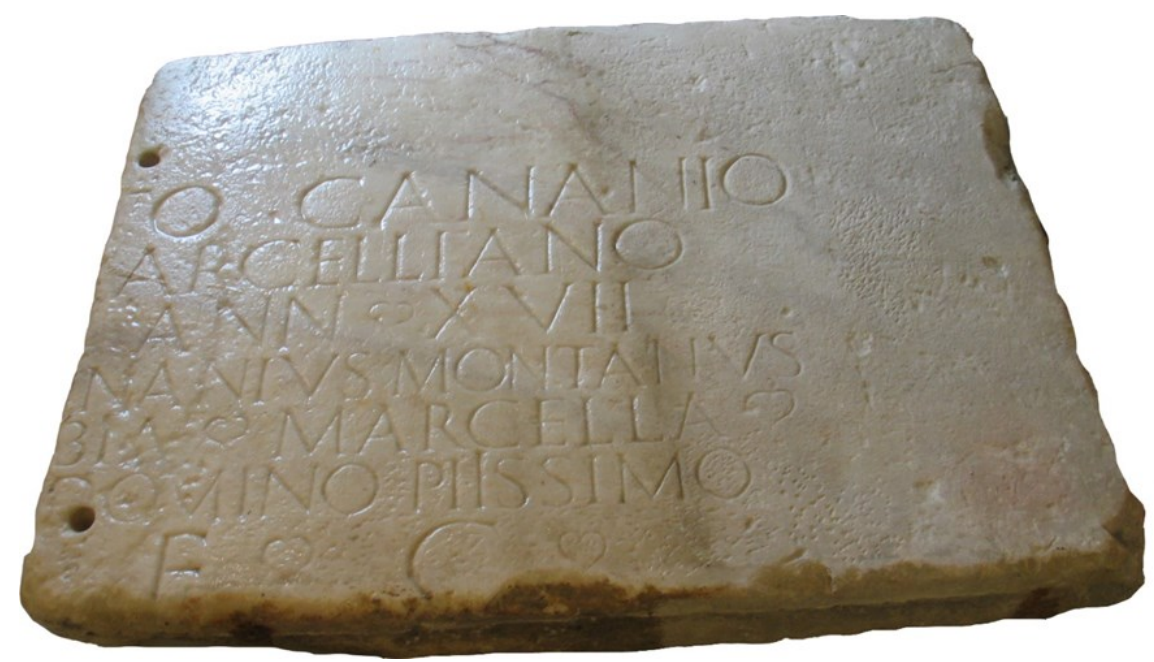

Fig. 2. Fotografía de detalle del epígrafe de Cela. Imagen cedida por el Museo Arqueológico Provincial de Pontevedra.

Fig. 2. Image of the inscription from Cela. Image courtesy of the Provincial Archaeological Museum of Pontevedra.

\subsection{Estudio epigráfico}

Se trata de una placa de grandes dimensiones, con un tamaño total conservado de $69 \times 93 \times 10 \mathrm{~cm}$, donde el alto de las letras oscila entre los 4,5 (1. 4, 5 y 6$)$ y $6,5 \mathrm{~cm}(1.1$ y 7).

Aunque la pieza esté incompleta por su parte izquierda, la paginación parece muy cuidada, siguiendo el texto un eje vertical. Esto y el esmerado ductus dan prueba de la profesionalidad del lapicida que ha combinado perfectamente los trazos anchos (verticales y diagonales en sentido superior izquierdo a inferior derecho) con los estrechos (horizontales y diagonales en sentido inferior izquierdo a superior derecho) e $i$ longa (1.6) de valor diacrítico9; o hederae distinguentes con forma de corazón (1. 3, 5 y 7) cuya función, más que separar palabras, es centrar lo máximo posible el texto.

Esta paginación centrada hace que propongamos una nueva restitución del texto que falta en la parte izquierda. a) Transcripción ${ }^{10}$

$[\mathrm{Sex}]$ to Cananio
$[M]$ arcelliano

$\operatorname{ann}($ orum $) \widetilde{\mathbf{e}}$ XVII

[. $\mathrm{Ca}$ ]nanius Montanus

5 [et Fa]bia $\widetilde{\boldsymbol{E}}$ Marcella

[h(eredes)] domino piissimo

$\mathrm{f}($ aciendum $) \widetilde{\boldsymbol{E}} \mathrm{c}$ (urauerunt)

b) Traducción

A Sexto Cananio Marcelliano, de 17 años. Cananius Montanus y Fabia Marcella, herederos, se preocuparon de hacerlo para su piadosísimo dueño.

\footnotetext{
${ }^{8}$ También está catalogada por el Servizo de Arqueoloxía de la Xunta de Galicia como ACH36033003.

Rodríguez Adrados 1971: 164-165.

${ }^{10}$ Ediciones precedentes y variantes de lectura: $C I L$, II, 5614: 1. 1 [Ti] to Cananio, 1. 4: [Ca]nanius Montanus, 1. 5: [Fa]bia, 1. 6 domino piissimo; IRG, III, 39: 1. 1: [...?]to Cananio, 1. 4: [Ca]nanius Montanus, 1. 5: [Fa]bia, 1. 6 domino piissimo; CIRG, II, 135 (así como HEp 1996: 752 y Redentor 2017: II, 173): 1. 1 [Ti] to Cananio, 1. 4: $[\mathrm{Ca}]$ nanius Montanus, 1. 5: $[\mathrm{Fa}]$ bia, 1. 6 [ex t(estamento) $]$ domino piissimo.
} 


\section{c) Consideraciones sobre el texto}

Observando el fragmento que resta de la placa (Fig. 3), la restitución de la primera línea [Ti]ṭo propuesta por los editores anteriores conllevaría que el texto estuviera ajustado a la izquierda junto con la segunda línea que comienza indudablemente por $[M]$ arcelliano. Por otro lado, la posición de las letras de la séptima línea apunta a un eje vertical central $^{11}$. Aunque no es imposible, no parece oportuno proponer que el texto esté escrito siguiendo dos ejes diferentes. Teniendo en cuenta que sólo el eje vertical central es seguro, pensamos que es más razonable una restitución en que todas las líneas del texto sigan dicho eje ${ }^{12}$. Así pues, en primer lugar, proponemos un praenomen más largo como Sextus para esta primera línea (Fig. 4). Bien es cierto que éste no tiene representación en la zona, sin embargo hay que tener en cuenta que nos hallamos en un contexto geográfico donde los testimonios de praenomina en general escasean ${ }^{13}$. De la misma manera, teniendo en cuenta la búsqueda de simetría del lapicida, añadimos al principio de la cuarta línea una letra que precede $[C a]$ nanius y que representa el praenomen del primer dedicante ${ }^{14}$. En la quinta se añadirá la conjunción copulativa et $\mathrm{y}$, en la sexta, se restituirá $[h($ eredes $)]$ en lugar de [e (x) t(estamento)], propuesta anteriormente. A partir de esta proyección centrada de la paginación estimamos que el campo epigráfico original medía aproximadamente $50 \mathrm{~cm}$ de alto por 86 de ancho y que la pieza entera, asumiendo que el campo epigráfico se hallaría en el centro de esta, llegaría a los $91 \mathrm{~cm}$ de alto por 135 de ancho.

Por lo que respecta a la onomástica, el interés se centra en el nomen Cananius, de origen incierto. En efecto, el resto de la onomástica de la placa es totalmente romana, ya sea en lo que se refiere al origen de los antropónimos como a su estructura. Presentamos a continuación algunas hipótesis para esclarecer el origen de este nomen a partir de los escasos paralelos que existen.

En primer lugar, A. Redentor (2017: I, 236237) opina que puede tratarse de un nomen creado a partir del topónimo de la Bética Canania o municipium Cananiensis en la actual Alcolea del Río ${ }^{15}$.

Por otro lado, Cananius podría ser un fósil onomástico de origen romano o itálico, es decir un antropónimo que no presenta casos en la península Itálica de donde sería originario y que apenas tuvo dispersión en el resto del imperio a parte de algunos casos muy aislados. Uno de estos se encontraría en Langres, Andematunum, en Germania Superior, donde tenemos Canani $m(\mathrm{anu})$ en una marca de alfarero $^{16}$, aunque este genitivo viene de un nominativo Cananus y no Cananius como nos lo indican dos inscripciones de la misma ciudad $(C A G, 52-02: 147)^{17}$. Si bien esta posibilidad no debe descartarse, hay que precisar que la onomástica de Langres es gala y, por extensión, céltica ${ }^{18}$.

De hecho -y esta es la tercera posibilidad-, es muy probable que se trate de un nomen de sustrato céltico. El paralelo más plausible se halla en Torres, en el alto valle del Guadalquivir, provincia de Jaén, donde una inscripción no céltica sino íbera datada entre 101-94 a.C. presenta el antropónimo kananike (MLH, III, H.5.1). Este antropónimo es considerado ajeno al íbero ya que no sigue una secuencia fonética propia de esta lengua ${ }^{19}$.

Además, según M. L. Albertos ${ }^{20}$, Cananius debe ponerse en relación con Canus de *kasno (gris), de modo que tiene un origen indoeuropeo ${ }^{21}$. A esta raíz se le supondría un sufijo -anius $<*$-anyos. El mencionado kananike podría ser un préstamo de una lengua indoeuropea (muy probablemente céltica ${ }^{22}$ ) con una sufijación - ke íbera ${ }^{23}$.

Pensamos pues que es muy probable que tanto Cananius como sus paralelos antroponímicos, incluso el del caso íbero, tengan un origen céltico. No hay que descartar un origen autóctono, es decir que provenga de una lengua céltica hablada en la zona, pero tampoco se puede dejar de lado la posibilidad de un origen en cualquier otro lugar del área de sustrato de las lenguas célticas, incluso la península Itálica.

Sobre el hecho muy poco frecuente ${ }^{24}$ (ya resaltado en $C I R G$, II, 135: 320) que los liberti que dedican la inscripción se refieran al difunto como dominus en lugar de patronus remitimos a la discusión en Redentor (2017: I, 292-293).

\section{d) Datación}

Por el superlativo, la fórmula final y la paleografía, se encuadra en el s. II d. C.

\footnotetext{
${ }^{11}$ A menos que no se deba restituir al principio de esta séptima línea una hedera distinguens, lo que parece difícil si comparamos esta posibilidad con la distancia en que las otras hederae distinguentes se intercalan con las letras en dicha línea.

${ }^{12}$ Evidentemente, esta hipótesis no es segura al cien por cien. No es imposible que la primera parte del texto estuviera alineada a la izquierda, pero tal alineación es menos habitual y habría que aceptar una irregularidad para con la séptima línea.

${ }^{13}$ Ver sobretodo la tabla comparativa en Redentor 2017, p. 174, para el conventus Bracaraugustanus aś como la escasez de praenomina documentados más al norte (CIRG II, p. 357; CIRG I, p. 229). Bastante más al sur tenemos ejemplos en Coria (CIL, II, 779) o en Vila Viçosa (CIL, II, 131).

${ }^{14} \mathrm{Si}$ bien A. Redentor (2017, p. 174) apunta para este caso que la identificación de los dedicantes puede ser menos completa que la del difunto.

${ }^{15}$ CIL, II, 1182; Navarro 2017: 64

${ }^{16}$ CIL, XIII, 10010: 426.

${ }^{17}$ Agradecemos al profesor J. Edmondson estas consideraciones.

${ }^{18}$ En este sentido, cabe mencionar también la ciuitas de los Cananefates (AE, 2000, 1022; AE, 2000, 1232; CIL, XVII, 587) en Germania inferior.

${ }_{20}^{19}$ Marques de Faria 2012: 94.

${ }_{21}^{20}$ Albertos Firmat 1966: 74-75.

${ }^{22}$ Coincidimos en esto con Marques de Faria 2012: 94. Para los paralelos célticos, ver Delamarre 2007: 55, Cananidonius y (gen.) Canani (citados en Marques de Coincidimos

${ }_{23}^{\text {Faria 2012: 94). }}$ Sobre la sufijación -ike, ver Rodríguez Ramos 2002: 127. Ver también nota 24 sobre la posibilidad de una adaptación íbera del etnónimo Cananeo.

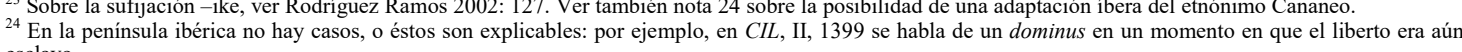
esclavo.
} 


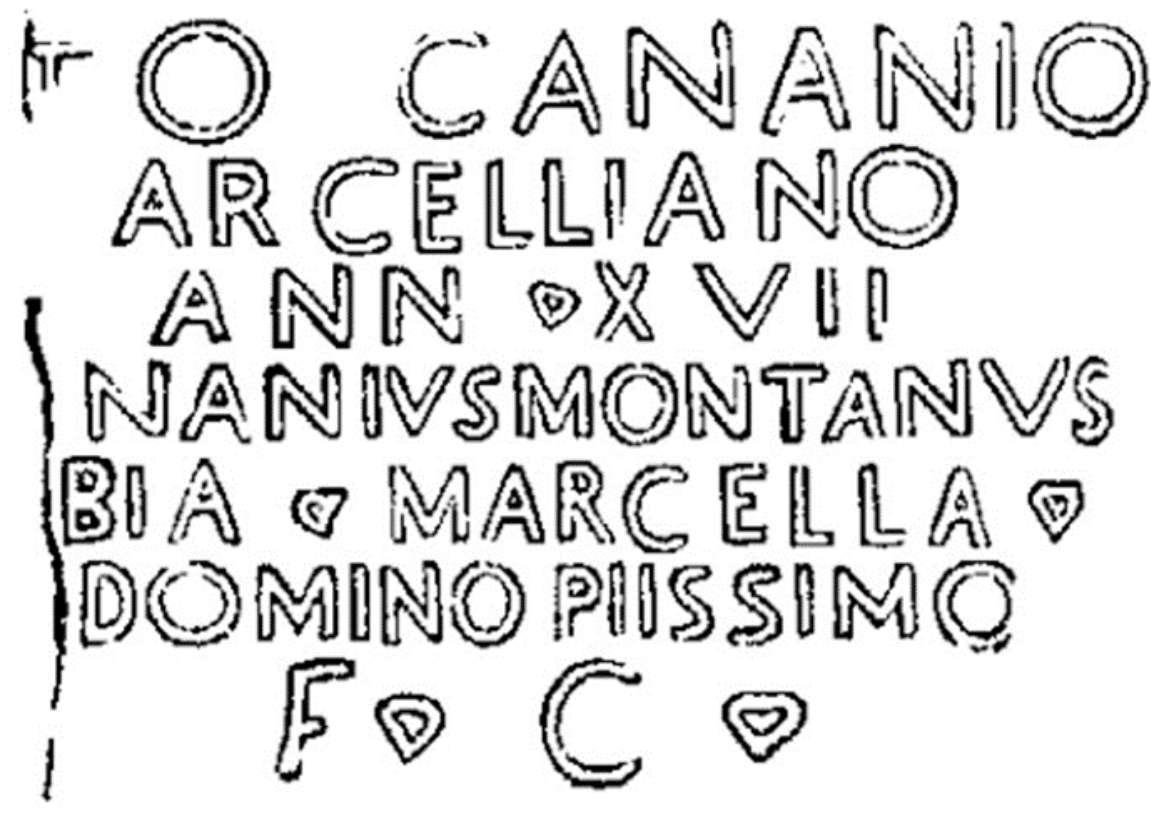

Fig. 3. Dibujo realizado por el padre Fita (Fita \& Fernández-Guerra 1880: 92) del epígrafe de Cela. Fig. 3. Drawing by reverend Fita (Fita \& Fernández-Guerra 1880: 92) of the Cela's inscription.

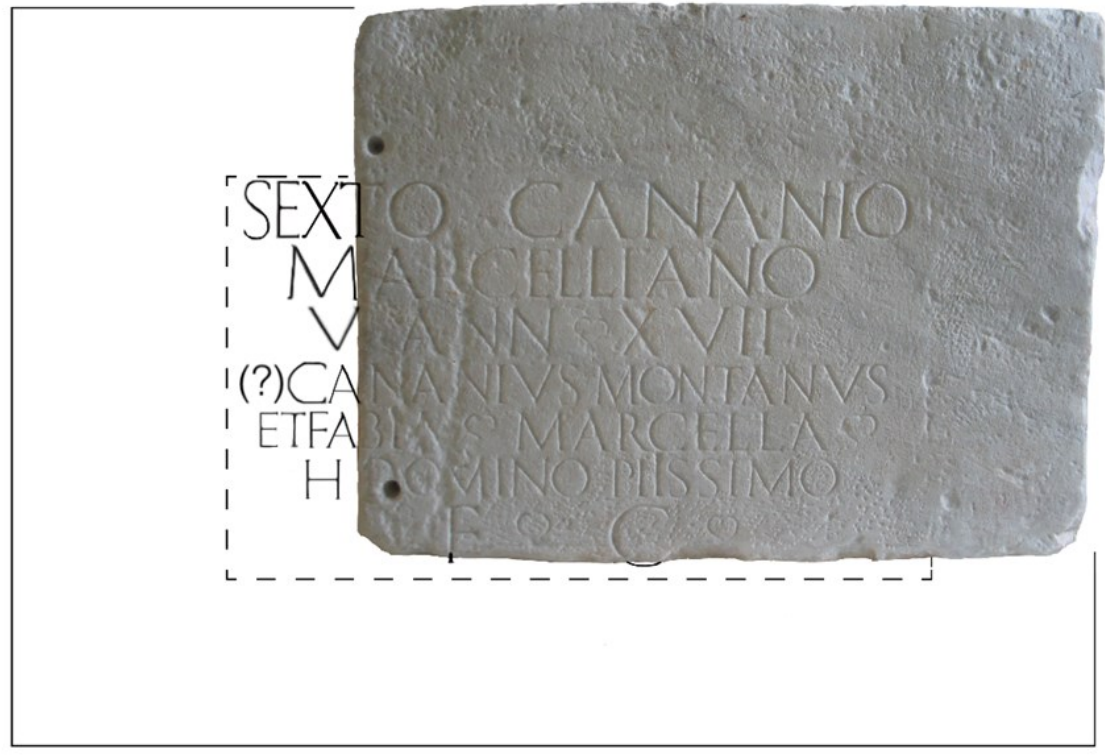

Fig. 4. Restitución del tamaño y la adaptación del texto a la nueva transcripción (por H. González Bordas). Fotografía cedida por el Museo Arqueológico Provincial de Pontevedra.

Fig. 4. Restitution of the size and the text, adapted to the new transcription (by H. González Bordas). Photography courtesy of the Provincial Archaeological Museum of Pontevedra. 


\subsection{Estudio arqueométrico}

\section{a) Planteamiento y protocolo analítico}

Junto al análisis epigráfico, el objetivo original de este estudio ha sido la caracterización litológica de la materia prima empleada como soporte material de este epígrafe. Así, si bien, como ya hemos apuntado se trata claramente de mármol, su estudio arqueométrico es un paso esencial para identificar el origen de este material, dato imprescindible a la hora de reconocer aspectos fundamentales como los procesos de producción y circulación de la pieza.

Como ha sido ya sobradamente demostrado, a día de hoy no existe una única técnica analítica que permita distinguir sin lugar a dudas los mármoles empleados en época antigua. Esta identificación debe, pues, ser abordada con estudios mineralógicos y geoquímicos, aplicados por igual en las piezas arqueológicas objeto de la investigación y en muestras de cantera, referencia imprescindible para identificar el origen de las primeras ${ }^{25}$. La aplicación de un protocolo de estudio multi-método que incluya estas técnicas, deseable en la mayoría de los materiales, es absolutamente imprescindible en el caso de los mármoles blancos puesto que sus características macroscópicas no son suficientemente discriminantes. Evidentemente, esta caracterización resulta más completa cuantas más técnicas se apliquen, valorando los resultados de varios análisis en conjunto en una aproximación "paso a paso" (Lapuente 2014; Royo 2016). Éste ha sido el planteamiento aplicado para la caracterización arqueométrica del epígrafe de Cela. En este caso, se ha valorado la petrografía macro y microscópica, con la incorporación de análisis puntuales mediante microscopia electrónica de barrido (SEMEDS), el estudio de catodoluminiscencia óptica (CL) y la espectrometría de masas de las relaciones isotópicas (IRMS) de carbono y oxígeno estables $\left({ }^{13} \mathrm{C} /{ }^{12} \mathrm{C} \mathrm{y}{ }^{18} \mathrm{O} /{ }^{16} \mathrm{O}\right)$ que han sido seleccionadas por su potencial discriminante.

Previo al estudio mineralógico y geoquímico, se ha realizado el análisis visual de la pieza mediante observación ocular directa llevada a cabo en su lugar de exposición actual ${ }^{26}$. Este paso es fundamental para evaluar rasgos y propiedades físicas globales del mármol tales como el tamaño de grano, el color o tonalidades, la presencia o no de veteados o laminaciones, el brillo, la transparencia y la existencia de zonas de alteración ${ }^{27}$. Todos ellos atienden principalmente a la composición mineral del mármol y permiten una primera clasificación preliminar, clave para su posterior discriminación.

El estudio microscópico necesita de la toma de una pequeña cantidad de materia, a partir de la cual se elabora, por un lado, la lámina delgada de $30 \mu \mathrm{m}$ de grosor imprescindible para la observación petrográfica y el estudio de catodoluminiscencia, y por el otro, una pequeña cantidad (c. 1 gr) de polvo para el análisis isotópico. En este caso, la muestra se tomó de una zona situada en la parte superior del lateral izquierdo de la pieza (Fig. 5, f). La elección de este lugar fue motivada porque presentaba una pequeña fractura anterior que facilitaba la extracción de un fragmento de material representativo de la litología global del mármol ${ }^{28}$ y a la vez porque su extracción en este lugar no afectaba en ningún ni caso el campo epigráfico ni las caras que conservan trabajo antiguo.

La observación de las características petrográficas se realizó mediante un microscopio óptico de luz polarizada ${ }^{29}$, con el objetivo de determinar no sólo la composición mineralógica del mármol mediante la observación del comportamiento óptico que presenta cada mineral-, sino también aspectos texturales-microestructurales y granulométricos de gran interés para el reconocimiento del material pétreo: textura, fábrica, tamaño máximo de grano o $\mathrm{MGS}^{30}$, forma de los límites de grano o $\mathrm{GBS}^{31}$, tipos de maclas (según la categorización de Burkhard 1993; Ferrill et al. 2004) y presencia/ ausencia de deformación intracristalina (Weiss 1954; Herz 1955; Lazzarini et al. 1980; Moens et al. 1988; Capedri \& Venturelli 2004). Estos parámetros son especialmente significativos en combinación con los resultados del análisis por catodoluminiscencia, basado en la capacidad luminiscente que presentan los carbonatos, en función de la concentración de algunos elementos traza presentes en la red cristalina -como el $\mathrm{Mn}^{+}$- o de la presencia de iones inhibidores -como los $\mathrm{Ni}^{+}$y Co $^{+}$- al ser bombardeados directamente por un haz de electrones en condiciones de vacío. Esta técnica se ha aplicado mediante un equipo de catodoluminiscencia óptica acoplado a un microscopio óptico de luz polarizada para su caracterización atendiendo al comportamiento luminiscente de la muestra en función de los parámetros de color, intensidad y distribución particular (Machel 1985; Machel et al. 1991; Habermann et al. 1998; Barbin et al. 1989, 1992; Blanc 1996, 1999; Casenave et al. 2003; Lapuente et al. 2000; Lapuente \& Royo 2016) ${ }^{32}$. Adicionalmente, en los casos en que el pequeño tamaño de los cristales hacía difícil su identificación mediante microscopía óptica de polarización y $\mathrm{CL}$, se ha recurrido al microscopio electrónico de

\footnotetext{
${ }^{25}$ Para un resumen actualizado de este aspecto, con especial énfasis y ejemplos del caso hispano, ver Lapuente 2014.

${ }^{26}$ Es decir, en la sala del Museo de Pontevedra dónde se encuentra expuesto.

${ }_{28}^{27}$ A ser evitados en el momento de la toma de muestra para el análisis arqueométrico.

${ }^{28}$ En este punto, el mármol no presenta vetas ni puntos alterados o erosionados que pudieran perturbar los valores analíticos. El fragmento obtenido es totalmente blanco.

${ }_{29}$ Modelo Leica DM2500 con un programa Leica Application Suite V3 (LAS) integrado, para la adquisición de imágenes, en el IRAMAT-CRP2A UMR 5060 (Burdeos, Francia). La preparación de la lámina delgada necesaria fue llevada a cabo por el Servicio de Preparación de Rocas y Materiales duros de la Universidad de Zaragoza (España).

${ }^{30}$ Maximum Grain Size, en la terminología habitualmente empleada en este tipo de estudios.

${ }_{32}^{31}$ Grain Boundary Shape.

CL 8200 Mk5-1 acoplado a un microscopio de luz polarizada Nikon Eclipse 50i POL de la Unidad de Estudios Arqueométricos (UEA) del ICAC; las imágenes fueron tomadas de forma controlada automáticamente (longitud focal: $29 \mathrm{~mm}$, apertura: f/4.6, exposición: $1 \mathrm{~s}$, ISO-200).
} 
barrido (SEM) para comprobar su composición y ayudar a su correcta identificación ${ }^{33}$.

A día de hoy, la espectrometría de masas de relación isotópica sigue siendo una de las técnicas más empleadas en el estudio de procedencia de mármoles antiguos. Consiste en el análisis de las relaciones isotópicas de los elementos ligeros (entre los que se encuentran los que forman parte de los componentes del mármol, es decir ${ }^{13} \mathrm{C} /{ }^{12} \mathrm{C}$ y ${ }^{18} \mathrm{O} /{ }^{16} \mathrm{O}$ ) lo que ayuda a diferenciar mármoles difícilmente distinguibles a simple vista, como son los blancos, formados en distintas regiones, en momentos cronológicos específicos y cuya historia geológica puede haber desarrollado características isotópicas específicas y diagnósticas. Los resulta- dos se expresan en notación delta $(\delta)$ habitual $\delta^{13} \mathrm{C}$ and $\delta^{18} \mathrm{O}$ mediante la relación de esta proporción en la muestra, en tantos por mil (\%o) respecto al estándar internacional PDB (Pee Dee Belemnite). $\mathrm{Su}$ aplicación junto con técnicas complementarias permite contrarrestar en cierta medida el alto grado de solapamiento de los valores relativos de cada una de las procedencias al que se ha llegado desde el gran desarrollo de sus estudios a partir de los años 80 y 90 del siglo XX (Herz 1987; Gorgoni et al. 2002; Attanasio et al. 2006). El análisis de la muestra extraída de nuestra pieza ha seguido el protocolo analítico habitual ${ }^{34}$ en estos estudios y puede verse, por ejemplo, en Gutiérrez Garcia-M. et al. 2016.
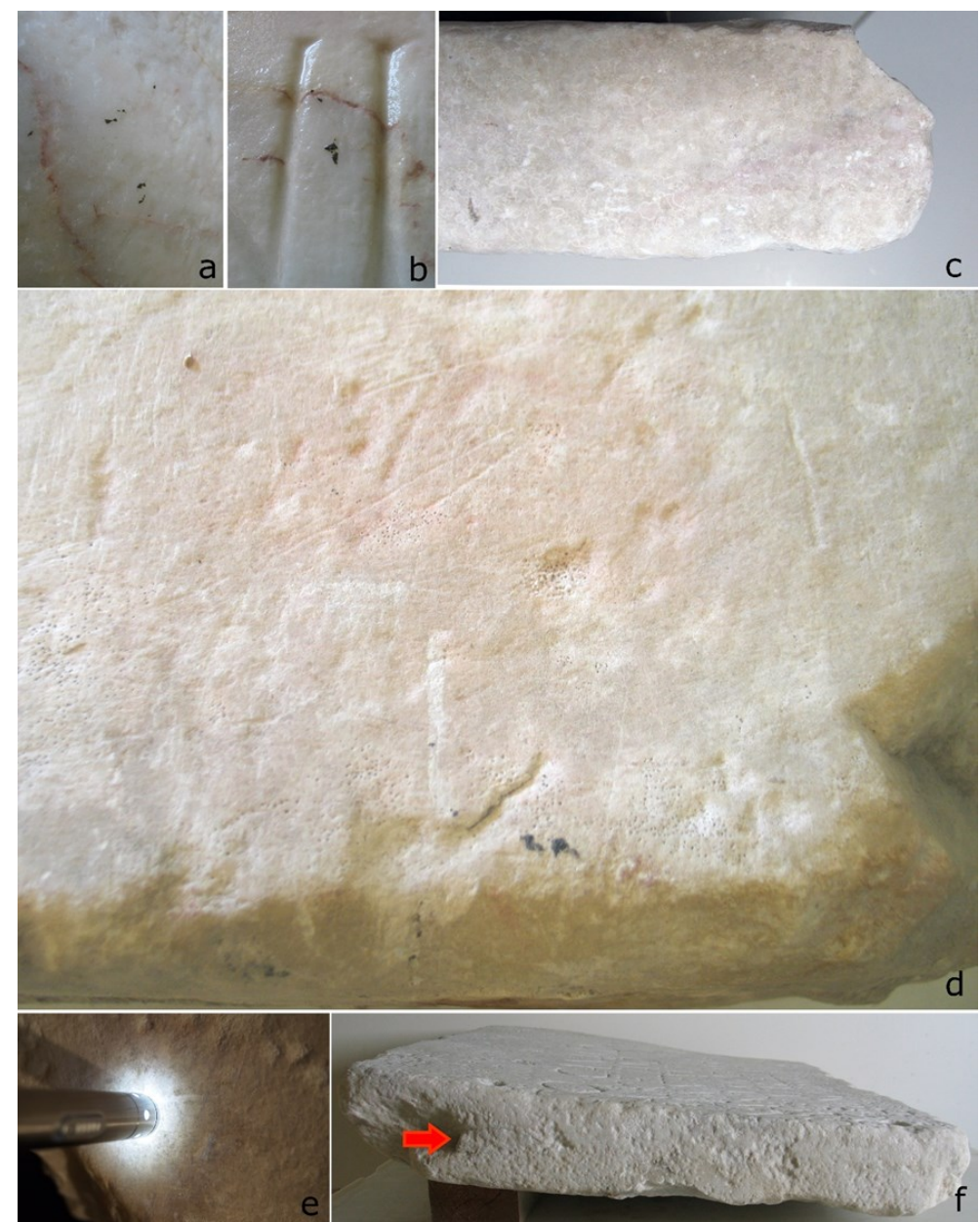

Fig.5. Diferentes vistas de detalle del aspecto macroscópico de la placa (a-b: vena rojiza justo antes y al cruzar las letras NI del nomen CANANIO; c-d: tono tenuemente rosáceo del mármol en el lateral superior y la esquina inferior derecha de la placa; e: comprobación de la translucidez del mármol) e indicación del lugar de extracción de la muestra, en el lateral izquierdo de la placa (f).

Fig.5. Different close-ups of the macroscopic traits of the plaque (a-b: reddish vein just before and when it crosses the letters NI of the nomen CANANIO; c-d: pinkish hue of the marble at the upper lateral and low right corner of the plaque; e: test of the marble translucence) and place from which a small sample was obtained (f).

\footnotetext{
${ }^{33}$ Modelo JEOL JMS $6460 \mathrm{LV}$, equipado con un espectrómetro de energía dispersiva Oxford Industries INCAx-sight, del IRAMAT-CRP2A UMR 5060 (Burdeos, Francia).

${ }_{34}$ Realizado en el Laboratorio di Isotopi stabili del Istituto di Geologia Ambientale e Geoingegneria (IGAG-CNR) en Roma, y llevado a cabo por M. Brilli, a quién queremos agradecer su colaboración, con un espectrómetro de masas de relaciones isotópicas-IRMS GasBench II.
} 


\section{b) Resultados}

En el caso del epígrafe de Cela, su buen estado de conservación permite apreciar que se trata de un mármol blanco de grano fino, compacto, bien cristalizado y significativamente translúcido (Fig. 5 , e). Presenta una vena color rojizo, muy fina y con algunas ramificaciones, que cruza la placa y el campo epigráfico en dirección aproximadamente diagonal desde la zona central superior hacia el lateral derecho (Fig. 5, a-b). Asimismo, y aunque difícil de observar según las condiciones de luz y posición, el examen minucioso de las superficies permite observar que blanco de este mármol presenta un tenue tono rosáceo en algunos puntos, como por ejemplo en el extremo derecho del lateral superior de la placa y cerca de la esquina inferior derecha - justo al lado del límite del campo epigráfico - (Figs. 2 y 5, c-d).

Microscópicamente se trata de un mármol de composición calcítica, textura granoblástica y fábrica anisótropa. Esta anisotropía viene marcada por diferentes microestructuras de foliación tales como la forma alargada de los granos de calcita, la presencia de una ligera orientación cristalográfica y sutiles variaciones de tamaño de grano siguiendo bandas granulométricas. Su tamaño de grano es, en efecto, fino y relativamente homogéneo, con un MGS de $1,3 \mathrm{~mm}$ y una media de $0,45 \mathrm{~mm}$ en la muestra analizada. Los cristales están relativamente bien trabados y uniformemente distribuidos, presentan unos bordes predominantemente rectos y curvos, con maclas únicamente de tipo I y II. No se observan signos de deformación intracristalina. Accesoriamente presenta pequeños cristales de cuarzo en posición inter e intracristalina. En menor proporción, se observan también micas de tamaño reducido $\mathrm{y}$, excepcionalmente, minerales opacos también de muy pequeñas dimensiones. El análisis por microscopio electrónico de barrido (SEMEDX) ha permitido comprobar la presencia de escasos granos de apatito, así como de cristales de dolomita extremadamente pequeños $(<100 \mu \mathrm{m})$. El estudio de catodoluminiscencia de la calcita determina una luminiscencia homogénea de intensidad débil y de color naranja oscuro (Fig. 6). Por lo que se refiere a sus valores isotópicos son de $2,06 \%$ en $\delta \mathrm{C}^{13}$ y $-5,21 \%$ en $\delta \mathrm{O}^{18}$ (fig. 7).
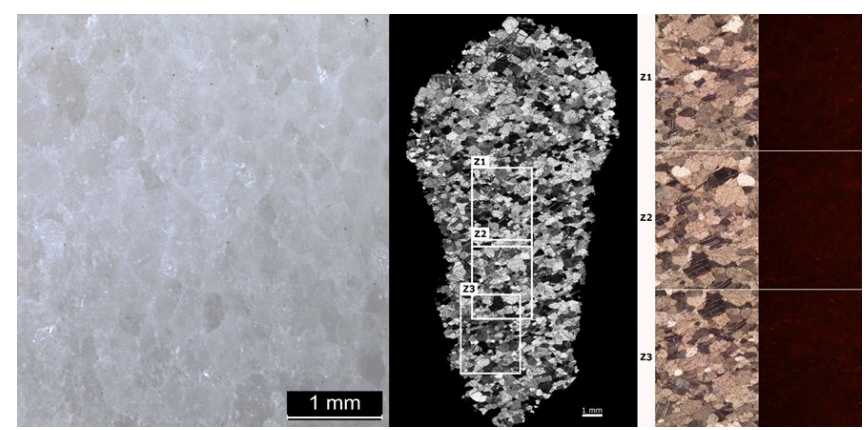

Fig. 6. Imagen del aspecto de la muestra, mediante observación con lupa binocular (izquierda); observación al microscopio óptico con luz natural e indicación de las zonas de análisis por CL (centro); y microfotografías con nícoles cruzados y respuesta luminiscente de las zonas de análisis seleccionadas (derecha).

Fig. 6. Image of the marble through stereomicroscope (left); microphotograph through optical microscope under plain light and indication of the zones that underwent $\mathrm{CL}$ analysis (center); and microphotographs in crossed polars and cathodoluminescence response of the selected areas of analysis (right).

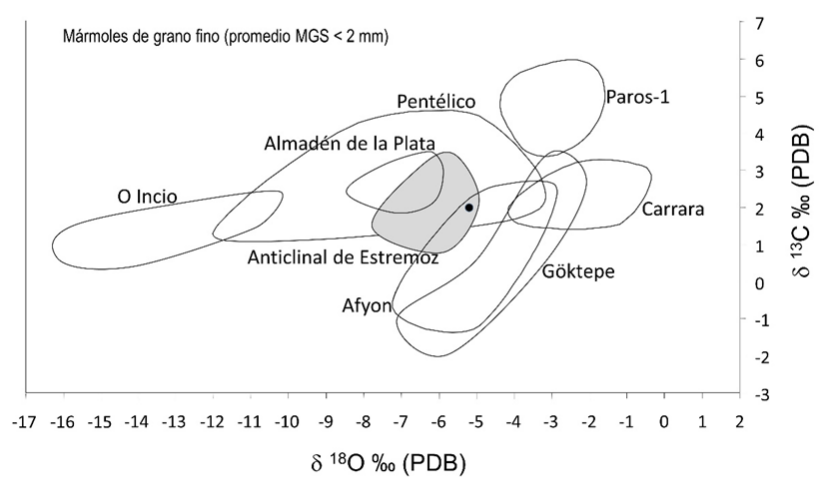

Fig. 7. Gráfico de relaciones isotópicas $\delta^{13} \mathrm{C}$ y $\delta^{18} \mathrm{O}$ en el que aparecen representados los valores de la muestra obtenida del epígrafe (punto negro) junto con los campos de distribución de los mármoles hispanos y clásicos con composición y tamaño de grano compatibles (Lapuente et al. 2000; 2014; Gorgoni et al. 2002; Attanasio et al. 2006; 2015; Gutiérrez Garcia-M. et al. 2016).

Fig. 7. Diagram of the isotopic relations of $\delta^{13} \mathrm{C}$ and $\delta^{18} \mathrm{O}$ with indication of the values from sample taken from the inscripcion of Cela (black point) potted against the distribution fields of the hispanic and Classical marbles of matching composition and grain size (Lapuente et al. 2000; 2014; Gorgoni et al. 2002; Attanasio et al. 2006; 2015; Gutiérrez Garcia-M. et al. 2016). 
c) Interpretación e identificación de la procedencia del mármol

Los resultados obtenidos se han comparado con muestras de referencia de los principales tipos de mármoles utilizados en época romana depositadas en las colecciones del Laboratorio para el Estudio de Materiales Lapídeos en la Antigüedad (LEMLA) de la UAB, del Institut Català d'Arqueologia Clàssica (ICAC), del Departamento de Geología de la Universidad de Zaragoza, así como con las bases de referencia publicadas de las más importantes fuentes de extracción de la cuenca mediterránea explotadas en la Antigüedad (Gorgoni et al. 2002; Attanasio et al. 2006; Lapuente et al. 2014; Antonelli \& Lazzarini 2015; Brilli et al. 2018). En este cotejo se han tenido en cuenta de forma especialmente significativa los valores de referencia de los mármoles hispanos, cuyo estudio ha permitido avanzar de forma significativa desde las últimas décadas del siglo XX (Cabral et al. 1992; 2001; Lapuente 1995, 2014; Lapuente \& Turi 1995; Lapuente et al. 2000; 2018, entre otros). Además, dado el lugar de localización de esta pieza y que no se podía descartar a priori que se tratara de un mármol local, también se ha comparado con aquellos mármoles del noroeste peninsular susceptibles de haber sido explotados en la Antigüedad y que presentan características macroscópicas similares (Cisneros Cunchillos et al. 2010-2011; Gutiérrez et al. 2016); esta comparación ha sido realizada en especial con muestras de mármoles gallegos y del NW leonés ${ }^{35}$ cuyo análisis y caracterización se está llevando a cabo dentro de una tesis doctoral centrada en el estudio y caracterización de los mármoles de esta región peninsular empleados entre la Antigüedad y la alta Edad Media ${ }^{36}$.

En primer lugar, los rasgos macroscópicos que presenta el mármol (venas rojizas y zonas de tonalidad rosácea perceptible en el blanco) lo distinguen de los principales mármoles blancos de grano fino procedentes de fuera de la península (Carrara de Italia, Pentélico de Grecia, Göktepe y Afyon -también conocido como Docimium- ambos originarios de Turquía) ya que los tres primeros en ningún caso presentan venas de color rojizo y en el caso del mármol de Afyon, aunque sí puede presentar este tipo de venas, su blanco es homogéneo y no muestra coloraciones rosadas. Si además tenemos en cuenta que sus valores isotópicos sólo son compatibles con dos de las cuatro canteras mencionadas (Pentélico y Afyon, Fig. 7), se pueden descartar de forma categórica las canteras de Carrara y de Göktepe como origen de la placa en estudio. En cuanto a los otros dos, a pesar de ser compatibles a nivel isotópico, las claras incompatibilidades petro- gráficas y especialmente en su respuesta catodoluminiscente, claramente heterogénea en los mármoles del Pentélico y de Afyon (Lapuente \& Royo 2016: 547, fig. 8), permite asimismo eliminarlos como posibles canteras de procedencia.

Por otro lado, las diferencias entre este material y las variedades de mármol blanco del NW hispano son igualmente claras. Por un lado, a escala macroscópica, el mármol blanco de grano fino de la zona de O Incio no presenta las mencionadas venas rojizas que se observan en la placa de Cela, y aunque sí suele presentar algunas heterogeneidades, estas consisten en venas naranjas y bandas grisáceas (Gutiérrez Garcia-M. et al. 2016), dándole un aspecto macroscópico muy distinto del de la placa en estudio. Los valores isotópicos confirman la eliminación del mármol de $\mathrm{O}$ Inicio como posible origen, puesto éste presenta valores de $\delta^{18} \mathrm{O} \%$ significativamente más negativos (Fig. 7). Por otro lado, el mármol blanco con vetas rosáceas identificado cerca de Tejedo del Sil presenta un tamaño de grano mucho mayor ${ }^{37}$, lo que permite también excluirlo.

No obstante, las características mineropetrográficas del mármol del epígrafe de Cela coinciden con las presentadas por ciertos litotipos del Anticlinal de Estremoz (Alto Alentejo, Portugal) y de Almadén de la Plata (Sevilla, España), ambas pertenecientes a zona Ossa Morena y cuyas similitudes visuales y petrográficas han sido ya señaladas (Lapuente et al. 2014: 334-337, y especialmente 346-348). Sin embargo, tal como estudios recientes han demostrado, tanto la respuesta a la CL como los valores isotópicos de estos mármoles hacen posible, en la mayoría de los casos, su discriminación (Lapuente et al. 2014: 346-348; Lapuente y Royo 2016: 456-457, fig. 7), lo que ha permitido en este caso llegar a discernir entre éstas dos posibles procedencias. En efecto, en el caso de la placa en estudio, la respuesta luminiscente (Fig. 6) es más próxima a las catodomicrofacies de intensidad baja presentadas por algunos mármoles del Anticlinal de Estremoz, en claro contraste con la respuesta mucho más intensa que suelen presentar los mármoles de Almadén de la Plata. Asimismo, los valores isotópicos del mármol en estudio lo sitúan claramente alejado del campo de referencia definido para el mármol de Almadén de la Plata mientras que cae perfectamente dentro del correspondiente al mármol blanco del Anticlinal de Estremoz (Fig. 7). Así, una vez considerados los datos macroscópicos y analíticos de forma combinada, se puede proponer con suficiente seguridad un origen en el Anticlinal de Estremoz para el mármol empleado para elaborar la placa encontrada en Cela (Mos).

\footnotetext{
${ }_{36}^{35}$ En la zona del Bierzo (León), y más en concreto, en Ambasmestas, San Fiz do Seo y Tejedo de Sil.

${ }^{36}$ Tesis doctoral titulada "Les marbres du Nord-Ouest de l'Espagne (actuelle Galice): contribution à leur caractérisation archéométrique ainsi qu'à l'étude de leur exploitation et usages durant l'époque romaine et le haut Moyen Âge”, y desarrollada por M.C. Savin, bajo la dirección de P. Lapuente (Universidad de Zaragoza) y R. Chapoulie (IRAMAT-CRP2A UMR 5060 CNRS-Université Bordeaux Montaigne). Esta tesis se enmarca dentro de los proyectos ROMAE y "Marmora Galicia" anteriormente mencionados.

${ }^{37}$ Alrededor de los $2 \mathrm{~mm}$ de MGS; la caracterización de este material se ha realizado en el marco de la tesis doctoral antes mencionada (vid. supra).
} 


\section{CONCLUSIONES}

Dentro del estudio global sobre materiales marmóreos de época romana y tardorromana localizados en el noroeste peninsular, nos encontramos, sin lugar a dudas, ante un epígrafe funerario de enorme interés tanto por su calidad formal y material como por la múltiple información que aporta desde distintas perspectivas. El hecho de que se verifique la procedencia del soporte como foránea, identificada en el Anticlinal de Estremoz (Portugal), es decir, de un ámbito central de la Lusitania romana, plantea por tanto interesantes cuestiones en torno a la razón de su traslado, así como al momento de importación de esta pieza al territorio galaico.

En ese sentido, la presencia de un epígrafe de esta entidad en el lugar de Cela tendría que ponerse en relación con la existencia en el entorno o en las proximidades de un monumento funerario significativo aún no identificado perteneciente a algún individuo cuyas posibilidades económicas le permitirían costear una pieza elaborada con un mármol de mayor calidad que los mármoles existentes en la zona, así como con un lapicida de gran maestría en su oficio.

Surgen, no obstante, varios aspectos a tener en cuenta en la interpretación de este epígrafe:

- $\quad$ Desde el punto de vista epigráfico, concordamos con los anteriores editores en que se trata de una inscripción con un ductus muy cuidado. Asimismo, proponemos una nueva restitución textual, teniendo en cuenta una ordinatio que sigue un eje vertical. A parte de la substitución de e $(x) \mathrm{t}$ (estamento) por $\mathrm{h}$ (eredes) en la penúltima línea, se añade la cópula et en la antepenúltima y, sobre todo, se incluye un praenomen, por desgracia indeterminado, para el primer dedicante (1. 4) y se propone un nuevo praenomen para el difunto (1. 1).

- Desde el punto de vista del material en el que fue trabajada dicha inscripción, estamos ante una pieza realizada posiblemente en el s. II d.C. en un material marmóreo foráneo, del ámbito lusitano del Anticlinal de Estremoz, lo que implica su importación desde un territorio alejado más de $500 \mathrm{~km}$. $\mathrm{Si}$ bien se confirma que el soporte procede de ese ámbito lusitano, ni el nomen Cananius (excepcional por su singularidad) ni ningún otro aspecto textual, permiten afirmar o negar que la inscripción haya sido realizada en otro contexto geográfico que no sea el correspondiente al lugar de su descubrimiento.
De acuerdo con estos aspectos, surgen las correspondientes preguntas sobre cuándo, cómo y por qué llega esta pieza a la parroquia de Cela, puesto que estamos ante una pieza descontextualizada, sin ningún referente arqueológico conocido que permita o ayude a su interpretación.

A partir de los datos disponibles, si bien es difícil confirmar fuera de toda duda su momento de importación al noroeste, consideramos plausible que el traslado de esta pieza se produjera ya en época romana. En efecto, además de la plena inclusión de este territorio en el Imperio Romano entre los ss. I-II d.C., y de la importancia geo-política y económica de la cercana mansio Tude (Tui) (Pérez Losada 2002; González Soutelo 2007), se suma a este argumento la ausencia de elementos que puedan apuntar claramente a un origen fuera del noroeste peninsular para el nomen Cananius. Igualmente, la confirmación de la llegada en época altoimperial de elementos elaborados en mármol del Anticlinal de Estremoz a lugares tan alejados de su zona de origen como, por ejemplo, Banasa y Volubilis, en el norte de África (Antonelli et al. 2009, 2015), o en Caesar Augusta (actual Zaragoza), importante puerto fluvial a orillas del río Ebro (Lapuente et al. 2016; Nogales et al. 2017), podrían reforzar la idea de la múltiple expansión de este mármol más allá de la Lusitania. Sin duda, en este caso además, hay que tener en cuenta la relativa facilidad de transporte de un soporte epigráfico tipo placa, ya bien fuera de forma finalizada -con el texto inscrito- o con la finalidad de ser grabada in situ en el ámbito $\mathrm{NW}^{38}$. En ese sentido, su transporte pudo haberse realizado por vía terrestre, retomando en su recorrido final el eje viario de la vía XIX del Itinerario Antonino que discurre por las inmediaciones de este lugar; o bien por vía marítima y fluvial, aprovechando la cercanía de este lugar a la costa atlántica (enclave de Vigo) y al río Miño.

No obstante, no podemos descartar completamente otros momentos de importación. Así, cabría la posibilidad de vincular su llegada al noroeste en el contexto de actuaciones de rapiñas o traslado de materiales hacia el norte de la Península tras época romana $^{39}$. En relación con ese fenómeno, querríamos resaltar fundamentalmente el episodio descrito en la Historia Compostelana (s. XII) sobre el traslado de diversas reliquias y materiales marmóreos por orden de D. Diego Gelmírez desde Portugal hacia la ciudad de Santiago de Compostela (Fandiño Fuentes 2017: 124) ${ }^{40}$. Concretamente, en esta obra recogida por el padre Flórez (1790: 40), se incluye la referencia a que, tras haber atravesado el río Miño a la altura de la ciudad de Tui y haber descansado con las reliquias en el monasterio de $\mathrm{S}$. Bartolomé situado en los suburbios de esta pobla-

38 Especialmente si tenemos en cuenta la distribución de elementos en mármol del Anticlinal de Estremoz relacionados con materiales voluminosos y pesados (como cajas y/o tapas de sarcófagos y placas decorativas), más difíciles de transportar, que sin embargo han sido atestiguados en varios puntos del norte y centro de la Península Ibérica (Fernández Ochoa et al. 2011; González Soutelo et al. 2018; Vidal Álvarez \& García-Entero 2015; Vidal Álvarez et al. 2017).

39 Como ya hemos planteado para otras piezas marmóreas del entorno (véase González Soutelo et al. 2018).

40 Cabe recordar que D. Gelmírez consigue el traslado de la dignidad arzobispal de Mérida a Santiago de Compostela en el s. XII, pasando a controlar la ciudad y los dominios del territorio de la antigua sede. Sobre este aspecto, remitimos, entre otros, al estudio recientemente publicado de Porrinas González (2018: especialmente pp. 662-672) 
ción, el siguiente lugar en el que se detendría la comitiva durante su camino a Santiago para su reencuentro con el arzobispo Gelmírez, sería justamente la iglesia de S. Pedro de Cela ${ }^{41}$.

Desafortunadamente, a pesar de esa coincidencia, el único dato documentado hasta el momento sobre el hallazgo de esta piezas se refiere a que la placa fue encontrada a mediados del s. XIX en el atrio de la iglesia, por lo que no existen indicios que permitan, fundamentar esa hipótesis más allá del contexto histórico y la referencia documental antes citada.

Fuese o no trasladada en época romana, lo cierto es que estamos, sin duda, ante una pieza excepcional y ante un nuevo ejemplo de materiales lusitanos (de mármol del Anticlinal de Estremoz) documentados en el noroeste peninsular. Así, junto al recientemente estudiado ejemplo del sarcófago de Tui (González Soutelo et al. 2018), y a otras piezas significativas ya publicadas como la cubierta del sarcófago de Ithacio o los relieves de Revillagigedo (Vidal Álvarez \& García-Entero 2015; Vidal Álvarez et al. 2017), contamos con un nuevo testimonio del interés por el empleo del mármol como material noble y por su traslado hasta este ámbito septentrional, siguiendo razones fundamentalmente de prestigio, lo que aparece testimoniado por la significativa dispersión y presencia de este tipo de elementos en todo el norte-noroeste peninsular.

\section{BIBLIOGRAFÍA}

Albertos Firmat, M.L. 1966.La onomástica personal primitiva de Hispania Tarraconense y Bética, Salamanca.

Àlvarez, A. \& Mayer, M. 1987. Le matériau des supports épigraphiques dans la zone nordest de la Tarraconnaise, Praktika tou diethnous Synedriou ellenikes kai latinikes epigraphikes, vol. II, Atenas: 5-9.

Attanasio, D.; Brilli, M. \& Ogle, N. 2006. The isotopic signature of classical marbles, Studia Archaeologica 145 , Roma.

Attanasio, D.; Bruno, M.; Prochaska, W. \& Yavuz, A.B. 2015. A multi-method database of the black and White marbles of Göktepe (Aphrodisias), including isotopic, EPR, trace and petrographic data, Archaeometry 57, 2: 217- 245 .

Barbin, V.; Ramseyer, K.; Decrouez, D. \& Herb, R. 1989. Marbles blancs : caractérisation par cathodoluminescence, Comptes-Rendus Académie des Sciences, Paris 308, II: 861-866.

Barbin, V.; Ramseyer, K.; Decrouez, D.; Burns, S.J.; Chamay, J. \& Maier, J.L. 1992. Cathodoluminescence of white marbles: an overview, Archaeometry
34: $175-183$.

Blanc, PH. 1996. La cathodoluminescence quantitative des marbres blancs. In: 119 e Congrès National des Sociétés Historiques et Scientifiques, Amiens 1994, Carrières et constructions III, Paris, Éditions du CTHS: 489-504.

Blanc, PH. 1999. Quantification de la cathodoluminescence des marbres blancs et de leurs mineraux accessoires. In : M. SchVoerer (Ed.), ASMOSIA IV. Actes de la Conférence Internationale ASMOSIA IV, 9-13 Octobre 1995. Archéomatériaux-Marbres et autres roches, Bordeaux, CRPAA-PUB: 45-54.

Braemer, F. 1986. Répertoire des gisements de pierres ayant exporté leur production à l'époque romaine. In : $\mathrm{F}$. Braemer (Ed.), Les ressources minérales et l'histoire de leure exploitation. Colloque international tenu dans le cadre du 108e Congrès national des Sociétés savantes, Grenoble 5-9 avril 1983, Paris, CTHS: 287-328.

Brilli, M.; Lapuente Mercadal, M.P.; Giustini, F. \& Royo Plumed, H. 2018. Petrography and mineralogy of the white marble and black stone of Göktepe (Muğla, Turkey) used in antiquity: New data for provenance determination, Journal of Archaeological Science: Reports 19: 625-642. https:// doi.org/10.1016/j.jasrep.2018.03.037.

BURKHARD, M. 1993. Calcite twins, their geometry, appearance and significance as stress-strain markers and indicators of tectonic regime: a review, Journal of Structural Geology 15: 351-368.

Cabral, J.M.P.; Vieira, M.C.R.; Carreira, P.M.; FigueireDo, M.O.; Penam T.P. \& Tavares, A. 1992. Preliminary study on the isotopic and chemical characterization of marbles from Alto Alentejo (Portugal). In M. Waelkens, N. Herz \& L. Moens (Eds.), Ancient Stones: Quarrying, Trade and Provenance, Leuven, Leuven University Press: 191-198.

Cabral, J.M.P.; MaCiel, M.J.; Lopes, L.; LoPes, J.M.C.; Maroues, A.P.V; Mustra, C.O. \& CARREIRA, P.M. 2001. Petrographic and isotopic characterization of marbles from the Estremoz Anticline: its application in identifying the sources of Roman works of art, Journal of Iberian Archaeology 3: 121-128.

CANTo, A.M. 1977-78. Avances sobre la explotación del mármol en la España romana, Archivo Español de Arqueología 50-51: 165-189.

Capedri, S. \& Venturelli, G. 2004. Accessory minerals as tracers in the provenance of archaeological marbles used in combination with isotopic and petrographic data, Archaeometry 46, 4: 517-536.

Casenave, S.; Chapoulie, R. \& Villeneuve, G. 2003. Cathodoluminescence of synthetic and natural calcite: the effects of manganese and iron on orange emission, Mineralogy and Petrology 78: 243-253. DOI:10.1007/S00710-002-0227-y.

CeÁn Bermúdez, J.A. 1832. Sumario de las antigüedades romanas que hay en España, en especial las pertenecientes á las Bellas Artes, Madrid, Miguel de Burgos.

41 "Translato sitaque per fluvii tranquillitatem Sanctos in Cenobio S. Bartholomaei, quod in Suburbio Tudae Civitatis situm est, posuerunt (...). Deinde Diaconus quem custodem deputatum esse praediximus, ex praecepto Pontificis supradictos Sanctos ad Ecclesiam S. Petri de Cella, quam B. Fructuosus fabrica verat, religiose detulit" (Flórez 1790: XX, 40). Quedaría la duda sobre la correcta interpretación de la iglesia-monasterio de S. Pedro de Cela con su ubicación actual, ya que el padre Flórez menciona que la iglesia que visita la comitiva en el s. XII, fue fundada por S. Fructuoso, cuando hasta el momento, como hemos indicado, no hay más datos sobre dicho edificio, ni existen testimonios materiales de esa primitiva construcción (Pereira Molares 2006: 204-205). 
CIRG I = BAÑos Rodríguez, G. 1994. Corpus de inscricións romanas de Galicia, Santiago de Compostela, Consello da Cultura Galega.

Cisneros Cunchillos, M. 1988. Mármoles hispanos: su empleo en la España romana, Zaragoza, Universidad de Zaragoza.

Cisneros Cunchillos, M.; Gisbert Aguilar, J. \& SomoviLLA DE MigueL, I.A. 2010-2011. El uso del mármol en la arquitectura de Asturica Augusta, Anales de Arqueología Cordobesa 21-22: 93-126.

Delamarre, X. 2007. Nomina Celtica antiqua selecta inscriptionum: noms de personnes celtiques dans l'épigraphie classique, Paris.

FandiÑo Fuentes, R. 2017. La "translatio" de los Santos Mártires de Braga a Compostela. Reflexiones sobre el capítulo I, 15 de la Historia Compostelana, Cuadernos de Estudios Gallegos, 64: 119-140.

Ferrill, D. A.; Morris, A. P.; Evans, M. A.; Burkhard, M.; Groshong JR. R.H. \& ONASCH C.M. 2004. Calcite twin morphology: a low-temperature deformation geothermometer. Journal of Structural Geology Acta, 26: 1521-1529.

Fita, F. \& Fernández-Guerra y Orbe, A. 1880. Recuerdos de un viaje a Santiago de Galicia[s.n.], Madrid.

FLórez, E. 1790. España Sagrada: teatro geographicohistorico de la iglesia de España: tomo XX, Historia Compostelana (segunda edición), Madrid, Antonio Marín.

González Soutelo, S. 2007. Tui antigo: Unha aproximación histórica-arqueolóxica, Serie Trivium, 24, Noia, Toxosoutos.

GonzÁlez Soutelo, S.; Gutiérrez Garcia-M., A. \& Royo Plumed, H. 2018. El sarcófago romano de Tui (Pontevedra): un ejemplo de la presencia de material marmóreo foráneo en el noroeste de la península Ibérica, $S P A L, 27.2$ : 229-246.

Gorgoni, C.; Lazzarini, L.; Pallante, P. \& Turi, B. 2002. An updated and detailed mineropetrographic and C$\mathrm{O}$ stable isotopic reference database for the main Mediterranean marbles used in antiquity. In: J.J. Herrmann JR., N. Herz \& R. Newman (Eds.), ASMOSIA V. Interdisciplinary Studies on Ancient Stone. Proceedings of the 5th International Conference of the Association for the Study of Marble and Other Stones in Antiquity, London, Archetype Publications Ltd: 115-131.

Gorostidi D. 2010. Ager Tarraconensis 3. Les inscripcions romanes, Documenta 16, Tarragona, ICAC.

Gorostidi, D. \& LóPEZ VILAR, J. 2015. La officina lapidaria tarraconense en época augustea: actualización del corpus y primeras consideraciones. In: J. López (Ed.), Tarraco Biennal. 2on Congrés Internacional d'Arqueologia i Món Antic. 26-29 novembre 2014. August i les províncies occidentals. 2000 aniversari de la mort d'August, vol. 2, Tarragona, ICAC: 257262.

Gorostidi, D.; LóPez VilaR, J. \& GUTIÉRREZ GARCIA-M.A. 2018. The use of Alcover stone in Roman times (Tarraco, Hispania Citerior). Contributions to the officina lapidaria tarraconensis, In: D. Matetić POLJAK \& K. Marasović (Eds.), Interdisciplinary Studies on Ancient Stone. Proceedings of the AS MOSIA XI Conference (Split), Split, University of Split: 545-550.

Gutiérrez Garcia-M., A. \& RodÀ, I. 2012. El mármol de Luni-Carrara en la fachada Mediterránea de Hispania. In: S. Keay (Ed.), Rome, Portus and the Mediterranean, London, Archaeological Monographs of the British School at Rome: 293-312.

Gutiérrez Garcia-M., A.; Royo Plumed, H.; González Soutelo, S.; Savin, M.-C.; Lapuente, P. \& ChaPOULIE, R. 2016. The marble of O Incio (Galicia, Spain): quarries and first archaeometric characterisation of a material used since Roman times, $\mathrm{Ar}$ chéosciences. Revue d'archéometrie,40: 103-117.

HabermanN, D.; Neuser, R.D. \& Richter, K. 1998. Lower limit of Mn2+-activated cathodoluminescence of calcite: state of art, Sedimentary Geology, 116: 1324

Herz, N. 1955. Petrofabrics and classical archaeology, American Journal of Science, 253: 299-305.

HERz, N. 1987. Carbon and oxygen isotopic ratios: a data base for Classical Greek and Roman marble, $\mathrm{Ar}$ chaeometry, 29: 35-43.

IRG III = FilgueIra VAlVerde, J. \& D'Ors, Á. (eds.) 1955. Inscripciones romanas de Galicia III: Museo de Pontevedra, Santiago de Compostela, CSICInstituto Padre Sarmiento de Estudios Gallegos.

JORDÁN, Á. \& ANDREU, J. 2013. La presencia privada en los foros hispanos a la luz de dos programas epigráficos hallados in situ en Los Bañales (Uncastillo, Zaragoza). In: J.M. Iglesias GIL \&A. Ruiz GutiÉrReZ (Eds.), Paisajes epigráficos de la Hispania romana. Monumentos, contextos, topografias, Roma, Hispania Antigua, Serie Histórica, 9: 127-143.

LAPUENTE, P. 2014. Archaeometry on stones. Multi-method approach to investigate stone provenance. Studied cases from Roman Hispanic marmora, Archaeometry Workshop 2014/XI/3: 149-158.

Lapuente, P. \& Álvarez, A. 2012. Métodos para la identificación de los mármoles. In: V. García-Entero (Ed.), El marmor en Hispania: explotación, uso y difusión en época romana. Madrid, UNED: 73-90.

Lapuente, P.; Nogales-Basarrate, T.; Royo, H. \& Brilli, M. 2014. White marble sculptures from the National Museum of Roman Art (Mérida, Spain): sources of local and imported marbles", European Journal of Mineralogy 26: 333-354.

Lapuente, P.; Nogales-Basarrate, T.; Royo, H.; Brilli, M. \& SAVIN, M.-C. 2018. Grey and greyish banded marbles from the Estremoz Anticline in Lusitania. In: D. Matetić Poljak \& K. Marasović (Eds.) Interdisciplinary Studies on Ancient Stone. Proceedings of the ASMOSIA XI International Conference (Split 2015), Split, University of Split: $367-$ 375.

Lapuente, P. \& Turi, B. 1995. Marbles from Portugal: Petrographic and isotopic characterization", Science, Technology and Cultural Heritage, 4: 33-42.

Lapuente, P.; Turi, B. \& Blanc, Ph. 2000. Marbles from Roman Hispania: stable isotope and cathodoluminescence characterization, Applied Geochemistry. 15: 1469-1493.

Lapuente, P. \& Royo, H. 2016. Cathodoluminescence for the characterization of ancient marble: problems and research perspective. In: T. IsMAeLLI \& $\mathrm{G}$. SCARDOZZI (Eds.), Ancient quarries and building sites in Asia Minor. Research on Hierapolis in Phrygia and other cities in south-western Anatolia: archaeology, archaeometry, conservation, Bari, Ed. Edipuglia: 541-548

Lazzarini, L.; Moschini, G. \& Stievano, B.M. 1980. A contribution to the identification of Italian, Greek and Anatolian marbles through a petrographical study and the evaluation of the $\mathrm{Ca} / \mathrm{Sr}$ ratio, Archaeometry, 22: 173-183. 
MACHEL, H.G. 1985.Cathodoluminescence in calcite and dolomite and its chemical interpretation, Geoscience Canada, 12: 139-147.

Machel, H.G.; Mason, R.A.; Mariano, A.N. \& Mucci, A. 1991. Causes and emission of luminescence in calcite and dolomite. In: C.E. BARKER \& O.C. KoPP (Eds.), Luminescence microscopy and spectroscopy: qualitative and quantitative applications, Tulsa, SEPM Short course, 25: 37-57.

Marques de FARIA, A. 2012.Crónica de onomástica paleohispânica (19), Revista portuguesa de arqueología, 15: $87-112$.

MAYER, M. 1999. El paisaje epigráfico como elemento diferenciador entre las ciudades. Modelos y realizaciones locales, In: J. González (Ed.), Ciudades privilegiadas en el Occidente romano, Sevilla, Diputación Provincial de Sevilla: 13-32.

MHL = UNTERMANN, J. 1990. MonumentaLinguarumHispanicarum3, Die iberischen Inschriftenaus Spanien, Wiesbaden.

Moens, L; Roos, P.; De Rudder, J.; De Paepe, P.; van Hende, J. \& WaelKens, M. 1988. A multi-method approach to the identification of white marbles used in antique artifacts. In: N. Herz, \& M. WAELKENS (Eds.), Classical Marble: Geochemistry, Technology, Trade, ASMOSIA I (Luca, Italy, May 9-13, 1988), Applied Sciences 153, Boston, Dordrecht NATO ASI Series, Kluwer Publ. Co.: 243-250.

Navarro, M. 2017. Perfectissima femina. Les femmes de l'élite en Hispanie romaine, Bordeaux.

Nogales, T.; Lapuente, P. \& Rodà, I. 2017. A propósito de dos retratos de Caesar Augusta (Zaragoza). In: S. Lefebvre (Dir.), Iconographie du quotidien dans l'art provincial romain: Modèles régionaux. Actes du XIVe congrès international d'art provincial romain (June 2015, Dijon, France), Dijon, 44e suppl. à la Revue Archéologique de 1'Est: 261-270.

Pereira Molares, A., 2006. Arquitecturas y arquitectos en la diócesis de Tui: siglos XVII y XVIII, A Coruña Fundación Pedro Barrié de la Maza.

PÉREZ LosADA, F., 2002. Entre a cidade e a aldea: estudio arqueohistórico dos "aglomerados secundarios" romanos en Galicia, Brigantium 13, A Coruña.

Porrinas GonzÁlez, D. 2018. La conquista cristiana de Mérida en 1230, In: J.C. LóPez Díaz, J. JiménEZ Ávila \& F. Palma García (Eds.), Historia de Mérida. Tomo I: De los antecedentes de Augusta Emerita al fin del medievo, Mérida, Consorcio de la Ciudad Monumental Histórico-Artística y Arqueológica de Mérida: 650-687.

RAmírez SÁnchez, M. 2014. Paisajes epigráficos en la provincia Hispania Citerior en época de Augusto, Veleia, 31: 123-141.
Redentor, A. 2017. A Cultura Epigráfica no Conventus Bracaraugustanus (Pars Occidentalis): Percursos pela sociedade brácara da época romana, vol, I y II, Coimbra, Imprensa da Universidade de Coimbra Vol. I - https://doi.org/10.14195/9 78-989-26-12706, Vol. II - https://doi.org/10.14195/ 978-989-261441-0.

RoDÀ, I. 2005. La difusión de los mármoles pirenaicos en Hispania y la datación epigráfica de los inicios de la explotación de las canteras, In: J-P. Bost; M. Martín Bueno; J-M. RodDAz \& P. Le Roux (Eds.), L'Aquitaine et l'Hispanie septentrionale 'a l'époque julio-claudienne. Organisation et exploitation des espaces provinciaux. Colloque Aquitania (Saintes, 11-13 septembre 2003), Bordeaux, Aquitania supplément, 3: 461-471.

Rodríguez Adrados, J.V. 1971. Usos de la í longa en $C I L$ II. Emerita XXXIX: 159-168.

Rodríguez Colmenero, A.; Ferrer Sierra, S. \& Álvarez AsOREY, R.D. 2004. Miliarios e otras inscricións viarias romanas do noroeste hispánico: conventos bracarense, lucense e asturicense, Lugo, Consello da Cultura Galega, Sección de Patrimonio Histórico.

Rodríguez Ramos, J. 2002. Acerca de los afijos adnominales de la lengua íbera, Faventia, 24/1: 115-134.

Ruiz GutiérREZ, A. 2013. El paisaje epigráfico de la ciudad romana: Concepto y perspectivas de estudio. In J.M. Iglesias GiL \& A. Ruiz Gutiérrez (Eds.) Paisajes epigráficos de la Hispania romana. Monumentos, contextos, topografías, Roma, Hispania Antigua, Serie Histórica, 9: 13-27.

SusINI, G.1966. Il lapicida romano. Introduzione all'epigrafia latina, Roma.

SusinI, G. 1982. Epigrafia romana, Roma.

Vidal Álvarez, S. \& García-Entero, V. 2015. The use of Estremoz marble in late antique sculpture of Hispania: new data from the petrographic and cathodoluminescence analyses. In: P. Pensabene \& E. GASPARINI (Eds.), ASMOSIA X. Proceedings of the Tenth International Conference Interdisciplinary Studies on Ancient Stone, Rome, "L'Erma" di Bretschneider: 355-366.

Vidal Álvarez, S.; García-Entero, V.\& Gutiérrez GarCIA-M., A. 2017. La utilización del mármol de Estremoz en la escultura hispánica de la Antigüedad Tardía: los sarcófagos, DIGIART, 3: 119-128. https://doi.org/10.14195/2182-844X_3_14.

WEISS, L.E. 1954. Fabric analysis of some Greek marbles and its applications to archaeology, American Journal of Science, 252: 641-662. 